\title{
The psychoanalytic languages: On the intimate rivalry of Michael Balint and D. W. Winnicott
}

Accepted for publishing by Edinburgh University Press in Psychoanalysis and History, https://www.euppublishing.com/loi/PAH

\begin{abstract}
The article presents and discusses a two-decades correspondence between Michael Balint and D.W. Winnicott. Alongside closeness and friendship, the letters reveal tensions, disagreement and even rivalry between Balint and Winnicott on three main levels: personal, cultural and theoretical. The debate can be framed around the question of whether or not the British School of Psychoanalysis that emerged in the 1950s - and in which Winnicott and Balint were arguably the most senior figures - was a continuation of the psychoanalytic tradition that developed before the Second World War by Sandor Ferenczi and the Budapest School. The article argues, however, that there is another meta-theoretical level to the debate between the two: they passionately try to define what is the psychoanalytic language, and disagree about its real nature.
\end{abstract}

There's a story about D. W. Winnicott that has achieved almost legendary status that he raised his hand during the so-called Controversial Discussions between Kleinians and Anna Freudians, during World War II, in order to suggest that everyone should take shelter as there were some real bombings outside (Shapira, 2013. P. 102; on the Controversial Discussions see Pearl King and R. Steiner, 1991). This story was taken as a symbol for the heated debate within the room as a result of which psychoanalysts had lost touch with the reality of the war. Winnicott here appears as the voice of reason, who reminds everyone that keeping one's life safe is even more crucial than winning a theoretical debate, important as the latter might be. But this story also demonstrates the fact that Winnicott did not find the discussions very fruitful, and that for him the debate was rather boring than 'hot'. He could not find his 
voice during these meetings, and in the years to come he made an effort to offer a third way between the two main theoretical parties of British psychoanalysis. The outcome was the development of what is known as the 'object-relations' theory, and the establishment of the influential Independent Group within the Institute of Psychoanalysis - Winnicott was to become one of its prominent leaders. Winnicott, the paediatrician of Paddington Green Hospital, who in 1934 became Britain's first male child-psychoanalyst, also became one of the major winners of this historical debate.

But Winnicott was not alone in the building of the new postwar object-relations school, what Gregorio Kohon (1986) described as the British School of Psychoanalysis. The other major figure in the Independent Group was Michael Balint, who narrowly escaped from Hungary on the eve of the war, and in a few years became a leading figure in the Independent Group. This article explores a correspondence between Winnicott and Balint from the two decades in the 1950s and 1960s that they knew each other closely as the high-profile figures of the Independent Group at the Institute of Psychoanalysis in London. It demonstrates some of the their major theoretical agreements and disagreements; it presents their complicated friendship, wich was full of rivalries, envy, and sometimes even anger; it reveals wider questions about the possibility of different psychoanalytsst finding a common psychoanalytic language and what happenes when this common language cannot be fine; finally the correspondence raises some questions about the cultural differences between different psychoanalytic communities - in this cases Budapest and London and the possibilities as well as difficulties in the integration of one psychoanalytic culture into another.

Balint was already a known in continental psychoanalysis when he arrived in Britain and already knew some of the contenders in the Controversial Discussions. He was particularly recognized as Sandor Ferenczi's follower and his most prominent successor. In an interview he gave in 1965, Balint described his first meeting in Hungary with Ferenczi, which was also his first meeting with another future leading psychoanalyst here in Britain: 
- MB:[...] Ferenczi announced his lectures, ${ }^{1}$ I went and listened, I was very interested. I read the Interpretation of Dreams. I did not like it very much. Then, when Ferenczi finished it was the custom that we had to go to the lecturer and have all the lecture cards attested that we attended. So, I went to Ferenczi. It was a private room, a consulting room, I sat in the waiting room with my university card, waiting. That was the first time, in 1919, that I met Melanie Klein, who was Ferenczi’'s patient. She came out quite, well, as patients come out from analysis.

- Q: What you mean by that?

- MB: Well, rather disturbed, crying, and so on. So that was the first time we met. Later, when we became friends, we recalled this incident. Then I went in and told Ferenczi what I did not like in his lectures. It was very amusing. I was very young (Swerdloff, 2002, p. 385).

This first meeting of Balint and Klein in Ferenczi' 's consulting room took place at a crucial moment in the history of Hungary. In March 1919 the short-lived Hungarian Soviet Republic was established, led by the communist Bela Kun. The few months of what was known as the Commune were full of promise for psychoanalysis. Ferenczi became a Professor of Psychoanalysis in the University of Budapest - in fact the first ever Chair in Psychoanalysis. The Marxist philosopher and literary critic, Georg Lukacs, who became the Commissar of Education, was on the appointment committee. As the Hungarian sociologist Oszkár Jászi wrote in 1920: “During the revolutions ... Freudianism was the idol of Communist youth', (Eros, 2012, p. 44). Thus we should bear in mind that this first meeting of Klein and Balint, in Ferenczi's consulting room, came during one of the first periods - certainly not the last - when psychoanalysis contributed a radical political revolutionary movement. $^{2}$

However, this revolutionary experiment was short-lived, and by August 1919 the communists were defeated by the Fascist counter-revolutionary forces, led by Admiral Horthy. After the collapse of the Commune in August 1919, the new regime became very hostile to psychoanalysis, and by the late 1930s all members of what was

\footnotetext{
${ }^{1}$ cross reference to Ferenc Eros' article - ABSOLUTLEY - FEEL FREE TO ADD IT!

${ }^{2}$ On the history and historiography of psychoanalysis and radical politics see Bar-Haim, 2018.
} 
known as the Budapest School had either left the country or been forced underground. Indeed, already in the 1920s, many leading Hungarian psychoanalysts, such as Sandor Rado and Franz Alexander, emigrated to work in other places in Europe and the US. Michael Balint and his first wife, Alice - herself to become a prominent psychoanalyst - left to get their psychoanalytic training in Berlin, but they returned to Budapest in 1924. After Ferenczi died in 1933, Balint became his natural successor as the leader of the Budapest School, which at the time meant also fighting an ongoing struggle with the Fascist regime.

That was the political context in which Alice and Michael Balint decided to move to England in 1938, where they were assisted by Ernst Jones and John Rickman. Just after their arrival, in 1939, Alice Balint suddenly died. ${ }^{3}$ In 1948, after living several years in Manchester, Balint joined the Tavistock Clinic and moved to London. During the 1950s and 1960s he became recognized as one of Britain's leading psychoanalysts, and in 1968 - two years before he died - he was elected president of the British Psycho-Analytical Society.

However, the dialogue between the Budapest and the London schools of psychoanalysis did not start in 1939, when Balint moved to England, but much earlier, through the work of Ferenczi in the 1920s. Ferenczi thought highly of his 'AngloSaxon readers', because of what he considered as their 'broad-mindedness'(Ferenczi, 1926, p. 8) and because they 'often strive to view such opinions as mine quite without prejudice, whereas elsewhere these are turned down a limine on account of their novelty or their boldness' (Ferenczi, 1926, p. 8-9). Ferenczi acted as a mentor for a whole group of interwar British psychoanalysts, including Jones, Klein, Rickman and David Eder, Claud Dangar Daly, Estelle Cole and Samuel William Inman. Some of them, like Klein, implicitly distanced themselves from him in the late 1920. Jones, however, openly became one of Ferenczi's bitterest opponents from the mid-1920s (Eros, Szekacs-Weisz, and Robinson, 2013).

By the late 1920s Ferenczi was expressing his ever more controversial views on regression, trauma, counter-transference, and what he perceived as the inherent 'hypocrisy' of the psychoanalyst. Many psychoanalysts (especially Jones) started to

\footnotetext{
${ }^{3}$ On Alice Balint see Anna Borgos
} 
think of him as having lost his way. In 9 September 1932, after Ferenczi presented in Wiesbaden his most controversial paper, 'Confusion of Tongues Between the Adults and the Child' (Ferenczi, 1949), Jones wrote to Freud: 'He is, I am afraid, a sick man - also physically - and the impression he made was very pathetic [...]. It is terrible but also unprofitable - to make comparisons with the brilliant past' (Paskauskas, 1993 p. 707). After this lecture, Ferenczi became a pariah among the leadership of the international psychoanalytic community (Freud included), and a year later he died. ${ }^{4}$ Even so, the Ferenczian vocabulary - i.e., the emphasis on the role of 'maternal care' and regression in people's psyche - remained strong within certain psychoanalytical circles, especially in Britain, in the works of Klein, Winnicott, John Bowlby, and of course, Michael Balint (Bar-Haim, 2014; Szekacs-Weisz and Keve, 2012; Rudnytsky, 2002). Indeed, Ferenczi's theory concerning the importance of the maternal role, and his innovative approach to regressive treatments remained particularly prevalent in the different schools of psychoanalysis in Britain after the World War II.

In terms of theory, the British school of psychoanalysis emerged from the integration of local traditions of psychological thinking with specific notions adopted by continental psychoanalysis, in which the interwar Budapest School played a central role (Bar-Haim, 2014; Forrester and Cameron, 2017; Hinshelwood,1995; Richards, 2000). This 'knowledge in transit' - James Secord's useful notion - concerns not only the emigration of ideas from one country to another - and what is implicated in this transition - but also the ways in which people from one historical setting contribute to the circulation of knowledge in another (Secord, 2004). But what exactly this 'knowledge in transit' was, is difficult to pinpoint. The correspondence between Balint and Winnicott that I'll be exploring below reveals a disagreement over whether such genuinely 'Ferenczian' knowledge ever existed, and if so - what was the specific form of its transmission from Budapest to London. We know today that even after the great dispute between Ferenczi and Freud in the 1930s, the Ferenczian language still survived and many British psychoanalysts spoke it very fluently. But at the same time, Balint's postwar writings are not less British-School-oriented than Winnicott's

\footnotetext{
${ }^{4}$ Jones reneged on his promise to publish 'Confusion of the Tongues' in the International Journal of Psychoanalysis. It was eventually published in English only in 1949.
} 
publications, even if the latter implicitly tried - as some of the letters suggest - to label Balint as an 'outsider', a non-English psychoanalyst.

The letters published here constitute an exchange that took place between 1949 and 1966. They reveal tensions, disagreement and even a sort of a rivalry between Balint and Winnicott on three main levels: personal, cultural and theoretical. But in fact the last parameter - the theoretical one - appears less significant in these letters in comparison with the other two. Not only is the intellectual disagreement marginal here but the personal tension is actually the product of a deep agreement - not a disagreement - between the two on what they considered to be the most important psychoanalytic principles: namely, the maternal relationship as the core element for any psycho-social development, and the importance of the regressive dimension to any psychoanalytical account.

So, if the intellectual debate is not particularly important - what else do we have here? Is it a dispute over who should take the credit for some innovative concepts of the Independent School in its golden years? Are these two psychoanalytic giants providing us with some egoistic claims about who was there first? That might be a fair description. At the same time, however, the letters raise a real historical question about the intellectual sources of the British psychoanalytical movement. From the perspective of the historian of ideas, the debate can be framed around the question of whether, when Balint arrived in England in 1939, he brought with him in his suitcase the rich tradition of the Budapest School, almost as a transitional object, so to speak; or were both Balint and Winnicott part of the same psychoanalytic discourse that emerged in Britain after the war, and the fact that Balint was Hungarian and Winnicott was English is not really that important for our purposes? It is, then, a debate over the 'right' language for speaking psychoanalysis. Or, to put it differently, whether there is such a 'right' language.

\section{Winnicott language, Balint language}

Letters between Winnicott and Balint from the late 1940s, when Balint moved to London, demonstrate a mutual appreciation and willing to cooperate. For example, in 
a letter from 8 August 1950, Winnicott praises Balint's publication on 'Individual Differences of Behaviour in Early Infancy and an Objective Method for Recording Them' (Balint, 1945), in which he found 'many points of extreme interest. ${ }^{5}$ In another from 17 October 1951, Winnicott suggests to Balint that 'regression' - a concept that was so central to both analysts throughout - should be a major topic for discussion two years later in the 1953 IPA Congress in London. In 17 July 1952 Winnicott writes to Balint to cancel his participation in a forthcoming 'Regression weekend' 6 The reason for that, he explains, is 'partly because I feel that we have not managed to get the co-operation we hoped for', but he still encourages Balint to initiate more discussions on regression in the 1953 Congress in London. Regression was the main concept that Balint thought he had brought with him from Budapest as a 'gift' to his new colleagues in London, even if he also admitted that there needed to be more thinking about how to use this idea correctly. In 26 March 1953, in response to Winnicott's paper on his child patient Phillip, Balint writes: 'what is the force or attraction that brings people out of their regressed state?... The nearest to an answer is a short [paper] by Ferenczi who said somewhere that children must be "saturated" before being able to leave one form of gratification to go on to the next one. This is very attractive, but does not say much, and certainly what on earth is the real meaning of "being saturated"?"7 Answering this question was a common project of the two, but also a source for many disagreements and conflicts.

On 6 May 1954, Winnicott responded to Balint's paper given the evening before, entitled 'Fun Fairs, Thrills and Regression' at a Scientific meeting at the Institute of Psychoanalysis. ${ }^{8}$ In this talk Balint suggested for the first time the division of human characters into two types, which he named 'philobats' and 'ocnophiles' :'

Greek scholars among my readers will know that 'acrobat' means literally 'one who walks on his toes', i.e. away from the safe earth. Taking this word as my model I shall use 'philobat' to describe one who enjoys such thrills, from

\footnotetext{
${ }^{5}$ Institute of Psychoanalysis Archive [hereafter, IOPA], P43/C/A/22).

${ }^{6}$ IOPA, P43/C/A/22.

726 March 1953; IOPA, P43/C/A/22.

${ }^{8}$ Enid \& Michael Balint Papers, The Albert Sloman Library, University of Essex.

${ }^{9}$ Cross reference to Raluca's paper ABSOLUTLEY
} 
which can easily be formed the adjective 'philobatic' to describe the pleasures and activities, and the abstract noun 'philobatism' to refer to the whole field. We need another term to describe the apparent opposite of a philobat, one who cannot stand swings and switchbacks, who prefers to clutch at something firm when his security is in any way endangered. For this I propose 'ocnophil',

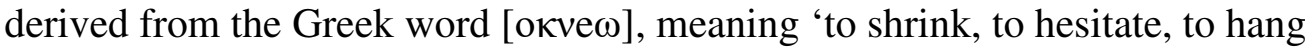
back'. Hence we get the adjective 'ocnophilic' and the abstract noun 'ocnophilia' (Balint, 1955, pp. 227)

Whereas the ocnophile lives in the illusion that as long as he is in touch with the safe object he is himself safe, the philobat's illusion is that apart from his own proper equipment he needs no object, certainly no one particular object. (ibid, pp. 228)

The philobat and the ocnophile are actually a mirror image of each other, both representing the same sort of anxiety, which is losing an object, or losing the object. ${ }^{10}$ For Balint, this initial anxiety is always about losing one's mother, or a regressive tendency to return temporally to the intimate relationship between the mother and her baby. Winnicott opposes Balint's usage of Greek terms, suggesting that Balint lacks the scholarly skills needed for such an intervention. Balint's theory has the potential to be valid, according to Winnicott, but remains vague and unclear. Nevertheless, he then summarizes perfectly well Balint's main suggestion of differentiating between characters 'who can operate in a highly regressive state in relation to a world that is not yet differentiated from what will eventually become the individuated self' ${ }^{11}$ People 'do not so easily get to this regressed state of primary identification but cling to a later phase in which there is an object to cling to, an object that is differentiated from the self'. [It might make sense ultimately to cross-ref some of these quotes to the pages of the letters themselves - for the moment you could put see p. xxx] So, even though he had been sitting at the back of the room, from where it was, according to

\footnotetext{
${ }^{10}$ Derry MacDiarmid made an interesting comparison between Balint's typology of 'philobat' and 'ocnophile' and Jung's well-known distinction between 'introverts' and 'extroverts'. See, MacDiarmid, 2013, pp. 145-148.

${ }^{11}$ Winnicott to Balint, 6 May, 1954, Enid \& Michael Balint Papers, The Albert Sloman Library, University of Essex..
} 
Winnicott, difficult to understand Balint's complex theory, it seems Winnicott understood it quite well.

Balint's reply arrives immediately afterwards, 7 May 1954:

I am sorry that you dislike my Greek terms, but the fact is that I was not able to find any English ones, and after all paranoia and schizophrenia, not to mention hysteria, obsession and phobia, are all Greek or Latin terms without which we could not even begin to think. Your promise that you will be converted to them after a Greek scholar has vetted them, I am afraid, already committed you as in fact they were not only vetted, but created jointly with a very eminent Greek scholar, Reader at Classics in Bristol University. ${ }^{12}$

A year later, in 9 March 1955, Balint commented on Winnicott's paper, later titled 'Withdrawal and regression'. In this paper Winnicott presented his theory of regressive treatment which, "carries with it the opportunity for correction of inadequate adaptation-to-need in the past history of the patient, that is to say, in the patient's infancy management' (Winnicott, 1954, p. 289). As mentioned above, this regressive approach was famously identified with Ferenczi, who believed that in treating patients who had previously suffered traumatic events, it is neither enough to remember what happened, nor to know the event's effects on the present: there must be a regressive emotional re-enactment of the trauma, which will include the patient's body as well as his or her mind. For Ferenczi, inducing a state of regression in the patient was at the core of the psychoanalytic treatment. He believed, paradoxically, that regression is both the illness and its cure: early traumatic events create severe regressive states, which in turn, can only be treated via clinically managed regression: '[a]nalysis must make possible for the patient, morally and physically, the utmost regression, without shame!' (Dupont, 1988, p. 116).

In his response to Winnicott's theory of regression, Balint does not oppose the former's meta-psychological and clinical suggestions, but reminds him that some of these ideas were suggested by others before in a different form. '[I]n a way I sympathize with you', Balint writes in a letter of 5 July 1955, 'It has always been my

\footnotetext{
${ }^{12}$ Enid \& Michael Balint Papers, The Albert Sloman Library, University of Essex..
} 
policy to read other people's ideas only after I have worked out my own to some degree. The only difference between us is that you do not like reading even after that point' ${ }^{13}$ Balint suggests to Winnicott that, if he had read more of Balint's own writings, he would have known that there were 'quite a number of points where our ideas come very close to each other'.

The same correspondence of summer 1955 contains some interesting exchanges between the two about the nature of language between analysts and their patients indeed, about the nature of language as such. Winnicott argues in a letter from 1 July 1955 that Balint's suggestion concerning the 'patient learning the analyst's language' is 'overdone'. Winnicott argues that even though both sides - patients and analysts need to learn the language of the other, still 'the language we talk on the whole is ordinary English' ${ }^{14}$ But while Winnicott presents almost a naïve perception of language, Balint questions the real nature of 'ordinary' language as such. It is true, he replied on the 5 July, that each analyst talks in 'the particular language of each individual patient', which means

that we talk about six to ten "languages"” every day, but all these languages are only dialects of one language, which is in your case Winnicott language and in mine Balint language. Then there are closely related language and languages very far apart from each other. For instance Milner language and Winnicott language are mutually understandable and it may be even difficult to say whether they are different languages or only different dialect. Almost certainly the same is true about the Malenesian and Paulinesian languages, and so on (ibid).

Balint describes the differences between these psychoanalytic 'languages' as 'clusters of associations' that determines the analytic work of the analyst. For instance, Balint proceeds, "you use the word "medium"; I would call the same thing either "friendly expanses" or "horrid empty spaces". It is possible that Kleinians might call it the

\footnotetext{
${ }^{13}$ IOPA, P43/C/A/22.

${ }^{14}$ IOPA, P43/C/A/22. One cannot avoid thinking about Winnicott's usage of the word 'ordinary' in a different text, namely his 1966 article on the 'The ordinary devoted mother' (CW7, 331-337).
} 
"good" and the "damaged" inside of the mother's body'. Each description may be correct 'at one given point in the analytic work'. However, the danger for the analyst is coming to believe that their perspective excludes any other possible perspective, and 'all the other aspects of the whole situation have to be pushed in the background, that is neglected, while using one description only'.

According to Balint, however, the attempt to use only one dominant "cluster of associations', and to push aside all other 'family of languages' (Balint's words) is almost inevitable. Sooner or later, the patient will have to learn and adapt her analyst's 'cluster of associations': 'every patient and his analyst enter into a tacit collusion to accept their own language and to develop it finer and still finer. In this way they only repeat what happens in every nursery between a growing baby and his ordinary devoted mother' (ibid).

Balint's philosophy of language as he presents it in this letter is deeply imbued with Ferenczi's later writings, especially his Clinical Diary (1988) and 'Confusion of the Tongues' (1949). Indeed, it is not a coincidence that Balint is so troubled with what he called 'the present analytic Babel' ${ }^{15}$ which so well echoes what Ferenczi described as 'confusion of tounges' (Ferenczi, 1949). But listening only to the Ferenczian language of this text is to miss a different discourse that was clearly dominant in British philosophy just at the same time, namely 'ordinary language philosophy', based on Wittgenstein's later writings, and famously articulated by Gilbert Ryle and J. L. Austin in postwar Oxford University. While as far as I know, there are no direct references by Balint to any of this group, there is more in common than we might think between the postwar 'object-relations' movement and postwar philosophy of language in Britain Chiara Alfano (2018) have shown recently that at the heart of Wittgenstein's critique of St. Augustine there is a different understanding of how infants learn their language, and whether or not they are born with a sense of interiority that guide them when acquiring it. Wittgenstein challenges a 'particular picture of a supreme and autonomous self'. In place of God-given brains, Wittgenstein puts the learning couple: teacher and child'(p. 29). As Alfano shows, this 'learning couple' is not so much different from the Winnicottian 'nursing couple'.

${ }^{15} 5$ July 1955 , IOPA, P43/C/A/22. 
In some of their major writings, Balint and Winnicott repeatedly suggested to study the major role of the non-verbal communications between mothers and children, as well as between analysts and their patients (e.g., Balint, 1955; Winnicott, 1965). ${ }^{16}$ In their correspondence, however, they both - like philosophers of language of that period - were totally preoccupied with understanding language and its true nature - in the consulting room and outside it, on the couch and off the couch.

In his handwritten reply to Balint (12 July 1955), Winnicott argues that words are not that important, it is only the meaning that matters:

You will agree that this matter of language is not the main thing - except that it becomes important in Society communications.

For instance I've never used the word medium anywhere else with a case; it just happened to turn up here and suited the man. It would be awful if people were to start talking to patients about mediums instead of providing the appropriate environment.

It's funny, but my comment on your ochnophillic [sic] paper was all to do with the words used. We both know that the important things in the two papers are the meaning and not the word.

It is relevant to compare the slightly naïve, or even dismissive, position on language that Winnicott expresses in his reply to a different exchange that he had a few years earlier with Melanie Klein. On 17 November 1952 he writes to her:

The first thing I want to say is that I can see how annoying it is that when something develops in me out of my own growth and out of my analytic experience I want to put it in my own language. This is annoying because I suppose everyone wants to do the same thing, and in a scientific society one of our aims is to find a common language. This language must, however, be kept alive as there is nothing worse than a dead language (Rodman, 1987, pp. 34). ${ }^{17}$

\footnotetext{
${ }^{16}$ See for example Winnicott's claim that 'what matters to the patient is not the accuracy of the interpretation so much as the willingness of the analyst to help, the analyst's capacity to identify with the patient and so to believe in what is needed and to meet the need as soon as the need is indicated verbally or in non-verbal or pre-verbal language' (1965, p. 122).

17 This letter is one of the most critical documents against dogmatism and sectarianism within the psychoanalytic movement in general and among 1950s Kleinian analysts in particular: 'I feel that
} 
Winnicott presents two very different understandings of language: 1) language as universal, transparent and self-explanatory; 2) language as singular and private. Balint is closer in his views to the second model, but he is mainly concerned with the dimension of power that is so dominant in the usage of any and every language, and that Winncott seems to miss altogether, i.e., the one who is in a stronger position will inevitably and unconsciously end up imposing his or her own psychoanalytic 'dialect'.

The arguments of Winnicott and Balint did not prevent them from acknowledging their many agreements, as well as their real sympathy and even intimacy. But they never stopped contemplating the right way of presenting similar notions through a particular language - 'Winnicott language' and 'Balint Language'. In 1958 Winnicott published (with R. E. Markillie) a highly positive review of Balint's book, The Doctor, his Patient and the Illness, published a year earlier (1957). The book was the outcome of Michael and Enid Balint's work with groups of general practitioners, and had a tremendous influence on the field of general practice in the decades to come (see Bar-Haim, 2018). Winnicott and Markillie praise the book as 'pioneer', 'important', and 'deserves to be most widely recommended among doctors, no matter what their practice may be' (Winnicott and Markillie, 1958). Balint had the chance to look at the draft in advance and was very grateful, saying how much he was 'terribly pleased that your views and mine are so much in harmony' ${ }^{18}$ But again in this case they both debate on language, when Winnicott criticize Balint's choice of words in two of the key concepts of his book - the doctor's 'collusion of anonymity' and 'apostolic function' (indeed, key notions for the Balint Group movement ever since). On the former Winnicott writes:

It is a question whether this term does in fact convey what the author intends to convey. I would suggest that the group is describing the scatter of responsible agents, and is showing how in certain cases this scatter has as its

corresponding to my wish to say things my way there is something from your end, namely a need to have everything that is new restated in your own terms...I am concerned with this set-up which might be called Kleinian which I believe to be the real danger to the diffusion of your work. Your ideas will only live in so far as they are rediscovered and reformulated by original people in the psycho-analytic movement and outside it' (Rodman, 1986, pp. 35). I'm very grateful to Lizzy Coles for referring me to this letter. See also Coles, 2014.

183 June, 1957, IOPA, P43/C/A/22. 
cause a psychiatric disorder in the patient or in one of the central figures of the social drama. (Winnicott and Markillie, 1958, pp. 426).

Balint sticks to his own language, saying that he has "no real objections to "scatter of responsibility", but 'collusion of anonymity' is 'somewhat better', before explaining to his friend Winnicott why he thinks so. ${ }^{19}$

The correspondence suggests very often a mixture of solidarity and envy, empathy and competition. In a letter of 27 March 1957, Winnicott wrote to thank Balint for presenting a paper in a meeting where Winnicott was the chair: 'I think the best part of [the paper] is that you start from a position of humility with the acknowledgment that we all have failures to our account. This is a great relief as compared with the tone of many speakers who seem to suggest that they can tackle everything' (Winnicott, 1963, p. 213). It seems Balint's acknowledgement of his failures and his ability to discuss them are indeed a great relief to his friend Winnicott.

On 5 Feb 1960, a day after Balint presented his paper on 'Primary Narcissism and Primary Love', Winnicott writes:

I very much envy the way you can draw on your knowledge of Freud's writings and can discuss these matters with a good deal of experience of the way things developed in fairly early days. I simply cannot take part in this kind of an exercise, although I can see its importance. Perhaps I would like to say that whereas I used to be absolutely unable to take part in a metapsychological discussion, I am now just beginning to be able to see a glimmer of light, so that if I live long enough I feel I might be able to join in from time to time. I do feel, however, that I shall always think that it is relatively unimportant the way Freud contradicted himself and gradually stimulated thought by making new suggestions. In a decade or two the people who mind about this will all be dead. (Rodman, pp. 127-8)

Here it was Winncott's turn to talk about his own failures, for example to understand what Freud said - however dismissive he is about this capacity. But the letter contains

193 June 1957, IOPA, P43/C/A/22. 
also an acknowledgement of the divergence between the two different languages Winnicott Language and Balint language - and a call to find a bridge between them:

Although we work from completely different angles and I think we have been uninfluenced by each other, you and I are both interested in the early environmental provision. I think we agree about what happens when there is a failure. Your word basic fault comes in here and I have had my own way of talking about these things. No doubt your statement of these matters preceded mine by many years. Where I find myself disagreeing with you is on the positive side and I must say that I really don't know the answer. (ibid, pp. 128).

\section{'...provided I never came to England': On Destructive Phantasies between Budapest and London}

Now let us turn to the final group of letters from 1966. Winnicott was at this time the President of the British Psychoanalytic Society, Balint would become the President two years later, and both were arguably the most senior analysts in the country, together perhaps with Anna Freud. On 8 December Winnicott wrote two letters to Balint. As with the previous exchange, these came a day after the two had had a public debate at the Institute of Psychoanalysis after Winnicott aired his paper on the 'Location of Cultural Experience' for the first time. Two main subjects were at stake: first, Balint's claim that this notion of the 'location of cultural experience' was taken from the Ferenczian legacy without giving any credit to Ferenczi or to himself; and, second, the fact that Winnicott forgot Balint's $70^{\text {th }}$ birthday. In the first letter Winnicott writes:

It is true that I have not studied your writings as well as I would like to have done, but that is not the point. I really know quite a lot about your contribution and I will be very surprised to find that you have dealt with the main subject that I was discussing last night. I will be very glad if you can show me where you deal with this. On the basis of last night's discussion I am going to try to write a fairly solid paper round my idea that I put forward, using the various things that were said in 
my discussion. I would so very much liked to have your comment and the expression of your feelings, anger included. I think that an underlying friendship can be solid enough so that we can say when we are angry with each other. ${ }^{20}$

Its seems like Balint accused Winnicott once again, of 'not doing his homework' before presenting new ideas that he claimed as original. However, 'The Location of Cultural Experience' contains fewer Balintian and Ferenczian ideas than Balint seems to suppose. In fact, it is one of Winnicott's most original pieces of work, with potentially broad theoretical implications in the fields of culture, politics and history. ${ }^{21}$ However, the letters reveal once again Winnicott's difficulties in acknowledging the influence of other people on his own work. In his reply (like Winnicott, in two different letters), Balint attacks Winnicott full-on:

Perhaps I ought to say here that this happened several times during our friendship. You emphasized on more than one occasion that 'though (I quote from memory) - Ferenczi and Dr. Balint have said all these many years ago, here I am not concerned with what they said', or 'I have not had time to read that but I shall ask the Honorary Librarian to fill this gap', etc. Of course in this way you always have the audience laughing and on your side - no-one among us likes to read boring scientific literature and if somebody of your stature admits it in public, he can be certain of his success... Your way of expressing your ideas forces one into the position of either saying "this is splendid and entirely new' or of remaining silent. ${ }^{22}$

I would like to conclude by arguably the most interesting section in this 1966 group of letters, namely, the somehow aggressive fantasy of Winnicott's that if Balint had not

\footnotetext{
${ }^{20}$ Enid \& Michael Balint Papers, The Albert Sloman Library, University of Essex.

${ }^{21}$ See, for example, Barbara Taylor's essay (2012) on 'Historical Subjectivity', where she puts forward Winnicott's notion of 'cultural experience' as a way of thinking anew the usage of empathy as a central concept in current historiography on subjectivity.

${ }^{22}$ Enid \& Michael Balint Papers, The Albert Sloman Library, University of Essex.
} 
come to England in the first place he - Winnicott - should not have had to share the glory, so to speak, with another senior analyst:

We all know that if you had been able to live in Hungary you would have a very high position not only in the psycho-analytical society of which you would have been by far the most senior member, but also in psychiatry and in the medical profession in the country. I feel that you have been very disappointed with the Society in this country and its failure to make use of you fully. In your own way you have forged a place for yourself in the medical profession and in a very wide circle of psychiatrists and medical practitioners all round the world, and it is from these people that you have no doubt had a large number of warm massages (Essex Archives). ${ }^{23}$

Winnicott surely was aware at the time of the tragic political situation in Hungary, only ten years after the Soviet invasion of Budapest. He probably also knew - in fact they both knew - that under the communist regime, psychoanalysis had to go underground, and therefore if Balint had been in Budapest at that time, not only would he have received no honours, but he would have been unable to present many of his psychoanalytical ideas publicly. This was precisely one of the reasons that he had to escape Hungary in the first place, even if it was under different circumstances and under a different oppressive regime. One may think of an even more radical interpretation, in which, symbolically speaking, Winnicott's fantasy was that the two people who met in Ferenczi's consulting room in 1919 - Balint and Klein - should not have come to London and should rather have stayed in Budapest, and thus would have been silenced one way or another. In a sense, it is a kind of acknowledgment that a transition of knowledge did happen, as well as a wish to return this knowledge to where it allegedly belonged. Therefore, I find the irony in Balint's reply quite intriguing, and perhaps the right words to conclude with:

Thank you very much for your fantasy about what sort of honours would have been accrued to me had I stayed in Hungary. I think you were entirely wrong. All my life, whoever I was, I didn't get on well with the 'Establishment', and as the honours depend largely on the

\footnotetext{
${ }^{23}$ Enid \& Michael Balint Papers, The Albert Sloman Library, University of Essex.
} 
good-will of the Establishment, I don't think the Hungarians would have been an exception to the general rule. Still, it was very kind of you to bestow all of them on me - provided I never came to England. May I be allowed to discern a little ambivalence in this construction, which may even be incorrect. ${ }^{24}$

As Balint suggests at the beginning of the paragraph above, Winnicott expresses a fantasy, and as such it cannot be 'incorrect' and must be a construction. This fantasy has some political, institutional and historical dimensions, but it also manifests an ongoing wish that Winnicott expressed in his letter to Klein, i.e., 'to say things my way... namely a need to have everything that is new restated in your own terms' (Rodman, 1987, pp. 34). As I have tried to show in this article, Balint's in-depth understanding of power-relations in using and adopting one's language, suggests that Winnicott's wish to 'say things my own way' is indeed a 'fantasy'. But the exchange between the two friends suggests that this fantasy was common to both of them, as well as a source for some ongoing disagreements and envy. It was also a source for close intimacy and perhaps even a friendship.

\section{References}

Alfano, C. (2018) Towards an ordinary language psychoanalysis: on scepticism and infancy. New Literary History, 49(1): 23-45.

Balint, M. (1945) Individual Differences of Behaviour in Early Infancy and an Objective Method for Recording Them. In: Balint, M., Problems of Human Pleasure and Behaviour. London: Routledge.

\footnotetext{
${ }^{24}$ Enid \& Michael Balint Papers, The Albert Sloman Library, University of Essex..Winnicoott's short reply from the 19 December 1966to Balint's is telling:

Dear Michael,

Thank you for your two letters.

I get your point.

Yours,

Donald
} 
Balint, M. (1955) Friendly Expanses—horrid Empty Spaces. International Journal of Psycho-Analysis, 36:225-241.

Balint, M. (1957) The Doctor, his Patient and the Illness. London: Pitman Publishing Co.

Bar-Haim, S. (2014) Regression and the Maternal in the History of Psychoanalysis, 1900-1957. Psychoanalysis and History 16(1):69-93.

Bar-Haim, S. (2018) 'The Drug Doctor': Michael Balint and the Revival of General Practice in Postwar Britain, History Workshop Journal,

Coles, E. (2014) Psychoanalysis and the Poem: On Reading in Sándor Ferenczi and D.W. Winnicott. New Formations: A Journal of Culture/Theory/Politics 83: 64-78.

Dupont, J.(ed.) (1988) The Clinical Diary of Sándor Ferenczi. Cambridge, MA.: Harvard University Press.

Erős, Ferenc (2012) Some Social and Political Issues Related to Ferenczi and the Hungarian School. In by Szekacs-Weisz, J. and Keve, T. (eds) Ferenczi and His World: Rekindling the Spirit of the Budapest School. London: Karnac.

Erős, F., J. Szekacs-Weisz, and K. Robinson (2013) Sandor Ferenczi - Ernest Jones: Letters 1911-1933 (eds). London: Karnac, 2013.

Ferenczi, S. (1926) 'Author's Preface'. In Further Contributions to the Theory and Technique of Psycho-Analysis. London : Karnac, 1994.

Ferenczi, S. (1949) Confusion of the Tongues Between the Adults and the Child(The Language of Tenderness and of Passion). International Journal of PsychoAnalysis 30:225-230.

Forrester, J., \& Cameron, L. (2017) Freud in Cambridge. Cambridge: Cambridge University Press.

Hinshelwood, RD. (1995) 'Psycho-analysis in Britain: points of cultural access 18931918', International Journal of Psychoanalysis. 76: 135-151. 
King, P. and, R. Steiner (1991) The Freud-Klein controversies, 1941-45. Hove:

Brunner-Routledge.

Kohon, G. (1986). The British school of psychoanalysis: The independent tradition. London: Free Association Books.

Macdiarmid, Derry (2013) Michael Balint: a Hungarian bastard. In Macdiarmid, Sue (ed.) Century of insight: the twentieth century enlightenment of the mind. London: Karnac.

Paskauskas, A. (ed.) (1993) The complete correspondence of Sigmund Freud and Ernest Jones, 1908-1939. Cambridge, Mass.: Belknap Pres.

Richards, G. (2000). 'Britain on the Couch: The Popularization of Psychoanalysis in Britain 1918-1940'. Science in Context, 13(2): 183-230.

Rodman, F. (1987). The Spontaneous Gesture: Selected Letters of D. W. Winnicott. Cambridge, MA: Harvard University Press.

Rudnytsky, P. (2002) Reading Psychoanalysis: Freud, Rank, Ferenczi, Groddeck. Ithaca, N.Y.: Cornell University Press.

Secord, J. (2004) 'Knowledge in Transit', Isis 95:654-672

Shapira, M. (2013) The war inside: psychoanalysis, total war, and the making of the democratic self in postwar Britain. New York: Cambridge University Press.

Swerdloff, B. (2002) An Interview with Michael Balint. The American Journal of Psychoanalysis 62(4):383-413.

Szekacs-Weisz, J. and T. Keve (eds) (2012) Ferenczi and his world: rekindling the spirit of the Budapest school. London: Karnac Books.

Taylor, B. (2012) Historical Subjectivity. In Alexander, Sally and Barbara Taylor, (eds) History and Psyche: Culture, Psychoanalysis, and the Past. Basingstoke: Palgrave Macmillan. 
Winnicott, D.W. (1949) The ordinary devoted mother. The collected works of D.W.

Winnicott. Edited by Lesley Caldwell and Helen Taylor Robinson. New York: Oxford University Press, 2017.

Winnicott, D.W. (1954) Withdrawal and regression. The collected works of D.W.

Winnicott. Edited by Lesley Caldwell and Helen Taylor Robinson. New York: Oxford University Press, 2017.

Winnicott, D.W. and Markillie, R.E. (1958). The Doctor, his Patient and the Illness. International Journal of Psycho-Analysis 39:425-428. 